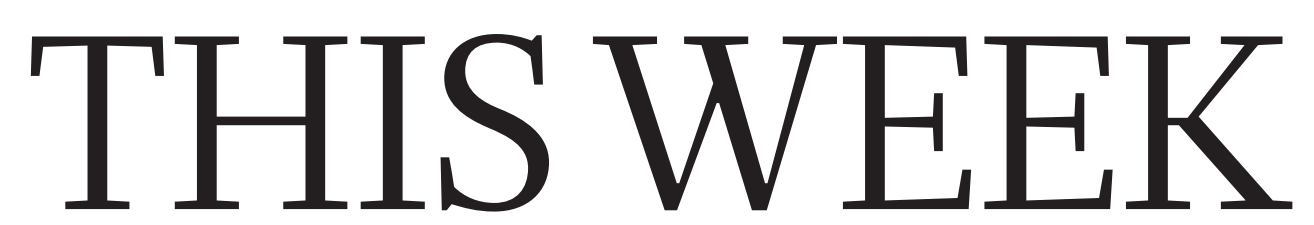

EDITORIALS

FAR SIGHTED Four hundred years of telescopes at a glance $\mathbf{p . 6}$
WORLD VIEW The developing world can and should do pure science $\mathbf{p . 7}$
MOONSHINE Chinese

home-brew beer kit is 5,000 years old $\mathbf{p . 9}$

\title{
Dark satanic wings
}

\section{Just as the dark-coloured pepper moth disappears from northern England, researchers are finally getting to the bottom of how it gained its colour.}

$\mathrm{N}$ ot for nothing was the region of the English midlands north of Birmingham called the Black Country during the late nineteenth century. It was the dark polluted heart of the industrial revolution, according to a railway guide from 1851: “The pleasant green of pastures is almost unknown, the streams, in which no fishes swim, are black and unwholesome; the natural dead flat is often broken by high hills of cinders and spoil from the mines; the few trees are stunted and blasted; no birds are to be seen, except a few smoky sparrows; and for miles on miles a black waste spreads around, where furnaces continually smoke, steam engines thud and hiss, and long chains clank, while blind gin-horses walk their doleful round.'

A few kilometres to the north, where trees remained, the wildlife was already adapting to its new human-made environment. You have all seen the results. The first famous dark-coloured peppered moth - a staple of textbooks - was recorded in Manchester in 1848 . Half a century later, they were everywhere. The wild-type, light-coloured and mottled, had disappeared almost to extinction.

There is perhaps no better example of natural selection in action than the case of the peppered moth (Biston betularia). As the same textbooks say, the colour of the moths evolved to match their new, sooty, backgrounds, and thereby camouflage the insects from hungry birds.

The story is not actually quite so clear-cut. Geneticists have squabbled over the details for decades - the strength of the evidence for the assumed choice of the birds, for example - and some of these technical criticisms have leaked, out of context, into the propaganda of creationists. In response, some textbooks have - heaven forbid - evolved to not include the peppered-moth story at all.

Among the holes in the story was the identity of the gene that was involved in producing the dark-coloured - melanic - moth variant.

Extensive mapping has pinned it down to a 400-kilobase region containing 13 genes, none of which had any obvious role in wing coloration. Undeterred, scientists went on to isolate the gene responsible, and they describe their search on page 102 of this issue. It is called cortex, orthologous to a gene of the same name in Drosophila. The researchers have even gone further, and shown that the specific cause of the mutation is the insertion of a transposable element (popularly, a 'jumping gene') into the first intron of the cortex gene.

The insertion leads to increased transcription of the gene during a phase of development when the wing discs are forming. The cortex gene, then, is involved in wing development, but there is still no obvious association with coloration. In Drosophila, cortex is involved in cell-cycle regulation, in particular, marking proteins that are redundant in the cell cycle as being ready for disposal. What is going on?

Work from a different group of Lepidoptera might offer a solution. In a study described on page 106, another group of researchers shows that cortex is a key player in the coloration of the wings of butterflies in the genus Heliconius, long a favourite for the study of mimicry. They show that cortex is a member of a fast-evolving scion of an

otherwise conservative group of cell-cycle regulator genes known as the fizzy family, a name redolent of activity, growth and fervour, and possibly involved in the regulation of wing-scale development. This is important, because it is the size, density and surface properties of the wing scales that determine colour in butterflies and moths. Flies, such as Drosophila, lack these structures, perhaps explaining why it was initially hard to associate the cortex gene with wing development.

There is a further, satisfying twist to the

"There is enough in the pages that follow to update the textbooks." tale. Although it is possible that melanic mutants existed undetected at a very low level in the peppered-moth population for centuries, the specific mutation behind their coloration is relatively recent, appearing around 1819 - in plenty of time for it to be noted down in Manchester a couple of decades later.

Much, of course, remains to be discovered, not least of which is the precise mode of action of cortex; how the gene relates to wingscale development; and how the insertion of a transposable element contrives to alter this. But there is enough in the pages that follow to update those textbooks. Still, future generations of readers will find it harder to recognize the high hills of cinders and spoil from the mines that drove the change. The air is cleaner these days, 'Black Country' is no longer an apt description, and the dark-coloured peppered moths are vanishing as quickly as they emerged..

\section{Toxic control}

\section{The United States is overhauling its chemicals law; now it must tackle carbon emissions.}

$\mathrm{T}$ The 1976 US Toxic Substances Control Act (TSCA) must be one of the worst pieces of environmental legislation ever devised. Rather than empowering the Environmental Protection Agency (EPA) to ensure that new chemicals are safe, the law declared all chemicals harmless, unless proven otherwise. The situation is so preposterous, in fact, that even the normally dysfunctional US Congress managed to unite last week to advance reform (see page 18 ).

The bipartisan TSCA reform bill passed the House of Representatives, by a vote of 403-12, on 24 May. Although senator Rand Paul (Republican, Kentucky) has temporarily blocked a vote in the Senate, the legislation is expected to pass in the coming weeks, clearing the way for a signature by President Barack Obama. Once that happens, EPA scientists will at last have the authority to do their jobs. 
Rather than watching passively as some 700 new chemicals enter all corners of the US marketplace each year, the EPA would be able to require companies to provide more data and conduct extra research to demonstrate the safety of the products. The legislation would also bolster review of existing substances. The TSCA inventory currently lists some 85,000 chemicals, but no one knows how many are still in use today. The EPA would create a new inventory and then sift through it to see which ones merit further investigation.

What is most remarkable about this reform legislation - aside from the fact that it took so long - is the list of supporters: Democrats and Republicans, both houses of Congress and the legislative branch, as well as many environmentalists and the chemical industry. The reason is simple: the companies that manufacture and use chemicals, once adamantly opposed to such reform bills, have realized that a viable federal regulatory system is in their financial interest. The complete lack of public confidence in the EPA's authority under the TSCA has pushed environmental officials at the state level to launch their own investigations and regulations. The upshot is that without a stronger federal system, the industry faces an increasingly complex - and uncertain - patchwork of regulations.

This is all good news for the public, which is bombarded daily by news reports, environmental campaigns and scientific studies that analyse the danger of one chemical or another in products that they purchase every day. It is also good for science. The new law will drive research into chemicals of concern, and companies will find it harder to claim that the information that they submit is a trade secret. As a result, more data will enter the public and academic spheres, and that is always a good thing.

Environmentalists pushed to ensure that the EPA's new decisions about health risks will be based on health data alone, without regard to economic implications. Under the new legislation, the EPA would be able to consider economic impacts in any subsequent cost-benefit

analysis only if it moves forward with regulations. And industry pushed for mandatory deadlines to ensure that decisions are made in a timely manner. All in all, it's a reasonable compromise that moves the regulatory needle in the right direction.

It is also a blueprint for what ultimately needs to happen to break the legislative stalemate on what is perhaps the greatest environmental challenge: the effect of greenhouse gases on climate.

"It's a

reasonable compromise that moves the regulatory needle in the right direction."

forced to pull their heads out of the sand
and think about reasonable solutions that are in line with their own political values.

Low-carbon energy such as nuclear power and that obtained from renewables would benefit the most, but natural gas would also get a short-term boost as utilities back further away from coal, which is already on the decline. Even coal would see its chances of survival increase in the long run, because properly agreed federal regulations would bolster the economics and interest in technologies that can be used to capture and sequester, or even use, carbon dioxide. At a minimum, with a legitimate set of rules in place, companies could move forward and plan their long-term investments accordingly.

Everyone could see that the original TSCA bill created a problem. It has taken decades, but reform was inevitable. The need for legal controls on the generation and control of greenhouse gases is just as clear - indeed, that is why the energy industry has fought so hard to undermine the evidence. This time, we do not have decades to waste.

\section{Seeing farther}

\section{Our fascination with telescopes and the worlds they reveal spreads beyond science into culture.}

$\mathrm{G}$ alileo Galilei did not invent the telescope, but he is generally credited with being the first to point one at the sky and record what he saw. Which begs a question: just what did the others before him do with theirs?

Ever since the great man saw and drew the moons of Jupiter in 1610, astronomers - both amateur and professional - have been captivated by the night sky. For more than 400 years, through revolution, war and endless change on Earth, telescopes have brought the rest of the Universe to us in ever-greater detail. We perch them on the tops of the highest mountains, strap them to aircraft, dangle them from balloons and launch them into orbit, all to get a better view of the world outside our own. We even cut holes in the roofs of our houses for them. The word 'telescope' derives from the Latin for far-seeing, and never can a scientific instrument have been so well labelled.

On page 34, Bernie Fanaroff, who as the former head of the Square Kilometre Array South Africa project knows a thing or two about telescopes, reviews a new account of their development and history. Eyes on the Sky by Francis Graham-Smith covers the entire spectrum, from existing instruments to planned ones that gather everything from long-wavelength radio waves to high-frequency X-rays. Readers with a taste for the bizarre could also check out Unusual Telescopes by Peter Manly, published in paperback in 1995. Among the weird and wonderful designs are telescopes with mirrors made from polished rock, inflatable telescopes and ornamental telescopes that double as sundials.

The names of some of the newest additions to the telescope roster - some barely off the drawing board - indicate where the field is heading. The Very Large Telescope will soon be joined by the European Extremely Large Telescope, but not by its cancelled rival, the Overwhelmingly Large Telescope.

But small instruments can be powerful, too, if there are enough of them. Maybe the future of astronomy lies not in ever-bigger adverbs but in tiny chips: a News story on page 15 offers a glimpse of that perhapsnot-too-distant technology. Next month, a package that holds dozens of Sprite mini-satellites is scheduled to be sent to the International Space Station, from where they will be released. It is a test run to gauge the potential of such 'chipsats' to swarm and collectively gather data on missions.

Next month will also see a telescope-related launch of a different kind - a new festival at the historic UK Jodrell Bank observatory near Manchester, headlined by the French musician Jean Michel Jarre. It was scientists at Jodrell who famously, with the help of a fax machine borrowed from the Daily Express, scooped the Soviets and intercepted the first pictures of the lunar surface from the Luna 9 mission. The glory days of that observatory may be behind it, but its status as an iconic landmark demonstrates another feature of telescopes: they provide a tangible link not just from astronomers to the Universe but from science to the wider public, especially when it involves an enormous radio dish. Indeed, the United Kingdom is seeking to have the site's cultural significance marked officially: Jodrell Bank is being considered for listing as a UNESCO World Heritage Site.

Telescopes and their discoveries have always spread beyond science. Shortly after Galileo drew Jupiter and its four moons, William Shakespeare is thought to have completed Cymbeline, one of his final plays. At its climax, the god Jupiter descends to the stage, preceded by four angels. Science and culture have never looked back, or so far. 